\title{
Special issue of the Francophone chapter of the International Society for Gerontechnology: A tribute to Alain Franco
}

\author{
Luigi Corrado EMBA ${ }^{\mathrm{a}}$ \\ Nathalie Bier PhD ${ }^{\mathrm{b}, \mathrm{c}, *}$ \\ Vincent Rialle $\mathrm{PhD}^{\mathrm{d}}$
}

\begin{abstract}
aPresident of the French Chapter of the International Society for Gerontechnology (ISG); ${ }^{\mathrm{b} C e n t r e}$ de recherche de l'Institut universitaire de gériatrie de Montréal, Montréal, Québec, Canada; 'École de réadaptation, Faculté de médecine, Université de Montréal, Montréal, Québec, Canada; 'University laboratory for Autonomy, Gerontology, E-health, Imagery Society (AGEIS, EA7407), University of Grenoble Alpes, France; *Corresponding author: nathalie.bier@umontreal.ca
\end{abstract}

\begin{abstract}
L.Corrado, N. Bier, V. Rialle. Special issue of the Francophone chapter of the International Society for Gerontechnology: A tribute to Alain Franco. Gerontechnology 2020;19(1):1-3; https://doi.org/10.4017/gt.2020.19.1.001.00 This special issue was prepared by the Francophone Chapter of the International Society for Gerontechnology (ISG) to honor Dr. Alain Franco, professor emeritus of Internal medicine and Geriatrics at Nice-Sophia Antipolis University Hospital (France) and founder of the Chapter. As an introduction to this special issue, we present the evolution of the Francophone Chapter, starting with the important contributions of Dr. Franco in its development and establishment, followed by its subsequent achievements and vision for the future.
\end{abstract}

Keywords: Gerontechnology, Francophone chapter, ISG

\section{INTRODUCTION}

Dr. Franco served as the president of the ISG from 2008 to 2013. Through his initiative, the Francophone Chapter (FC) was launched in 2010 , in Vancouver, during the $7^{\text {th }}$ World Conference of the ISG. The main goal of this new Chapter was to contribute to the development of the ISG by way of promoting the gerontechnology discipline among the French-speaking countries all over the world. It worked as an informal think-tank, in close cooperation with the French Society of Technology for Autonomy and Gerontechnology (SFTAG).

Just before its kick-off meeting, the FC was first outlined in the 6th ISG General Assembly in the following terms: "9.c. Francophone chapter, under construction". Dr. Gérard Cornet is the proposed president. The expected establishment is during the ISG World Conference Vancouver 2010. The expected number of ISG members joining the chapter is 35, both from European countries speaking French and in the Province of Quebec, Canada. Towards 2012, the following issues have a priority to be discussed more extensively: (i) evaluation methods, (ii) models for improving the development of gerontechnology applications from concept to market, and (iii) new frontiers for ethical issues". The kick-off meeting was mentioned within the ISG 2010 conference program with the title "Meeting of Francophone Chapter ISG" and took place on Friday, May $28^{\text {th }}(2010)$. It gathered about 30 French-speaking conference attendees.

At the outset, the contributions of the FC to the ISG were focused on master classes, conferences, and the proposition of symposia in the framework of the ISG World Congresses. The usual languages used within the chapter have always been French and English, with French being primarily used for internal works and English for larger diffusions within the ISG. The FC was first presided by Dr. Gérard Cornet (France; 20102016). He was followed by Dr. Vincent Rialle (France; 2016-2018) and currently by Mr. Luigi Corrado (Switzerland; 2018-now).

The three first symposia were fully organized by Dr. Cornet during his tenure.

(1) The first FC symposium, titled "Alzheimer's disease wandering behaviour: Gerontechnology and ethics", took place in Liège, Belgium, during the 2012 ISG conference, with contributions from C.F. Crispim jr et al. , V. Rialle et al., L. Corrado, and J. Petermans et al. 
(2) The second one, titled "Robotics for prevention and compensation of functional disability and social isolation at home", took place in Taipei, Taiwan, during the 2014 ISG conference with contributions from B. Maisonnier et al., D.J. Hewson et al., A. Ozguler et al., and R. Alami et al. (3) The third one, titled "Sustainable silver economy and humanity", took place in Nice, France, during the 2016 ISG conference, with contributions from N. Frontigny (France), L. Corrado (Switzerland), D. Abdelaziz (France), and H. Pigot (Canada).

The tenure of Dr. Rialle (2016-2018) began after these symposia. He was elected as FC president during the 2016 ISG (Nice, France) and started his tenure by organizing an important FC meeting with 20 members from four countries (US: 1, Canada: 4, Switerland: 2, France: 13) during this conference. The goal of this first meeting was to reflect on ways to increase the dynamism and internationalization of the Chapter. One of the main resolutions for enhancing the FC everyday functioning was to establish a social network for the FC members to exchange and communicate. Thus, a Linkedln group entitled 'ISG Francophone Chapter' was launched in October of 2016. However, there had been almost no use of this social network during the first year of functioning or the years that followed.

Afterwards, in order to efficiently boost and renew the FC, Dr. Rialle proposed to overpass the risk of its French centeredness (namely attested by the inappropriate, albeit enduring, expression 'French Chapter' used in various communications) by letting go of his FC presidency status to a valuable candidate to this important role from one of the French-speaking countries around the world. Moreover, he personally contacted some members of an international francophone research-and-action group (the DARAMS research group, http://rialle.eu/darams/) that he co-managed with Canadian, Swiss, North African, and French people in the area of technology for cognitive disorders. He invited them to consider being representative of vast regions (such as NorthAfrica, Canada, and Europe), and present themselves as candidate to the FC presidency. The SFTAG strongly supported this strategy of widely open international francophony that appeared to be quite promising for the next ISG conferences. In fact, with this new strategy, the three following continents were soon represented:

- Europe: Mr. Luigi CORRADO, EMBA, an architect by training, with a specialization in management and gerontology, former president of the 'Association Romande de Biotélévigilance'. He accepted to be the next president of the FC;

- Canada: Pr Nathalie BIER, PhD, Occupational therapist, researcher, Université de Montréal
École de réadaptation, and Research Center of the Geriatric University Institute of Montreal, Montreal (Quebec) Canada;

- Africa: Pr Abdelaziz DJELLAL, MSc, Head of a Nursing Retirement Home, expert of ageing in Africa, and Temporary Lecturer at the Faculty of Medicine Paris XIII, Paris;

Thus, truly began a new page of the FC. Through the initiative of its new committee, the FC took part in a session at the $11^{\text {th }}$ World Conference of Gerontechnology in St. Pertersburg, Florida, USA, as well as in a session at the International Francophone Congress of Geriatrics and Gerontology in June of 2018 (CIFGG 2018, https:// cifgg.viva-events.ch), in Montreux (Switzerland), to present the ISG and the FC. The FC chapter was also present at the congress "En Mode Senior" in Angers (France, https://www.enmodesenior2019.com/programme-congres) where the FC animated a symposium - "Ethics, new technologies and ageing".

Having the conviction that it is necessary to be involved widely to promote gerontechnology and the ISG in the French-speaking world, the President and the members who make up the FC have set themselves the following objectives to accomplish by 2021:

(1) Set up intra-chapter and intra-regional activities;

(2) Recruiting new members;

(3) Set up activities around the Francophonie relating to research, outreach and knowledge transfer;

(4) Develop international collaborations across the Francophonie by participating in projects that go beyond the borders of Europe (e.g. pilot projects on several sites, Canadian-European projects, or projects related to Francophone Africa);

(5) Organize symposiums, colloquia and scientific days;

(6) Create a website presenting the activities of the FC in connection with the ISG website, promoting scientific exchanges and articles;

(7) Setting up communities of practice to exchange on good practices in the field of gerontechnology;

(8) Actively participate in the next ISG congress to be held in May, in Norway.

The FC wishes to encourage the creation of a society in which technologies are accessible to both older and younger generations and is dedicated to developing this aspect in the Francophone world. This special issue thus provides an overview of the research currently being carried out in French-speaking countries and presents contributions more specifically from France and Canada. The following articles explore innovative technologies to support older adults to age well at home, such as smart environments 
(Lussier and collaborators; Tran and collaborators; Dupuy and Sauzéon), mobile technologies (Quillion and collaborators) and connected objects (Tellier and collaborators). The special issue also presents a novel approach to guide health professionals who support people with psychological and behavioral symptoms of dementia, via telepsychogeriatrics (Bruneau and collaborators). Finally, it presents a deep reflection on methodological tools and a specific case study to empower Gerontechnology research and efforts for building sustainable humanity (Rialle).

This special issue was made possible by the editorial contribution of Gérard Cornet, Nathalie Bier, and Luigi Corrado. Nathalie Bier is supported by a researcher award from the Fronds de la recherche du Québec - Santé. 